\title{
Sampling and farm stories prompt consumers to buy specialty cheeses
}

Barbara A. Reed
Christine M. Bruhn

$\nabla$

\begin{abstract}
California specialty cheese makers need information on what drives
\end{abstract} product sales so they can effectively market their products. Focus group and telephone research revealed that specialty cheese consumers have a strong preference for sampling cheese before making a purchase. Consumers also rely heavily on staff recommendations to select cheese. They appreciate unlimited sampling in an unhurried, low-pressure environment. Specialty cheese consumers consider themselves "food experimenters"; they value narrative descriptions about where and how the cheese was made and are not price sensitive in this area of their food purchases.

Canif alifornia's dairy industry is second only to Wisconsin's in cheese production. According to the California Department of Food and Agriculture (CDFA), California produced more than 1.6 billion pounds of cheese in 2001. Production is primarily in food service (commodity) cheeses such as cheddar (34\%), Monterey jack (11\%) and mozzarella (44\%). Hispanic cheeses (including queso fresco, panela, cotija and queso blanco) $(4 \%)$, other Italian cheeses (including ricotta, provolone, mascarpone and cacavallo) (3\%) and all other specialty cheeses $(3 \%)$ are tracked separately.

Commodity cheeses are used for food service products such as fast-food tacos or pizza, while specialty cheeses are a general category of unique cheeses. For example, Parmigiano Reggiano is a well-known specialty cheese made to very exacting standards within one region of Italy; it is identified by the traditional large rounds of cheese stamped with the consortium name. Many of
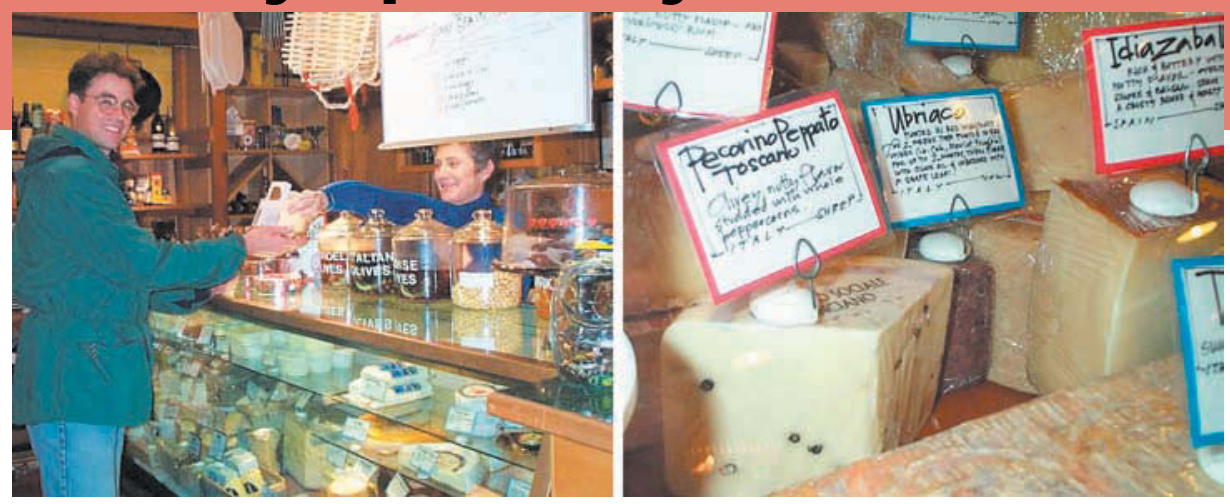

Over the past decade, consumers have developed a taste for "artisan" or specialty cheeses. Left, In focus groups, consumers said they rely on store staff and samples to help them choose new specialty cheeses. Right, Most specialty cheeses are displayed without formal packaging or fully visible labels. Case cards often describe cheeses without including the price.

California's specialty cheeses are described as "artisan" cheeses; they are made by hand in limited quantities and possess unique taste and quality characteristics that differentiate them from other cheeses. Likewise, "farmhouse" or "farmstead" cheeses are made with milk from the farm, on the farm.

Between 1993 and 2001, production of Hispanic cheeses almost doubled, increasing from 34.9 million pounds to 70.6 million pounds. Production of other specialty cheeses grew from 26.9 million pounds to 54.5 million pounds. Between 2000 and 2001, Hispanic cheese production increased by $8 \%$, and other specialty cheeses by $10 \%$ (CDFA 1998, 2002).

The California Milk Advisory Board (CMAB) surveyed more than 50 leading restaurants in San Francisco and the Napa and Sonoma valley wine regions about artisan cheese use in 1995 and again in 2000. In 1995, none of the restaurants had a cheese course, and few artisan cheeses appeared on menus. Now, nearly half of the restaurants list artisan cheeses on the menu as ingredients, and two-thirds feature cheese courses (CMAB 2002). California's artisan cheeses are also making inroads into specialty retailers such as Harry and David, and Dean and DeLuca. The increase in consumption of specialty cheeses over the last decade may be due in part to California's economic boom during the 1990s. People who had disposable income chose to spend it on high-end specialty foods, including cheese. Although we did not do a demographic profile of our interviewees, in general they were educated, well-traveled and made conscious choices about spending more than the average consumer on high-quality food.

Vertical integration of dairy production and specialty cheese processing allows dairy farmers to set prices that cover their production costs, rather than act as price takers in the commodity marketplace. Some California dairy producers have capitalized on the expansion of this market and are creating unique, handmade cheeses, in smallscale farmstead operations following European traditions. For example, the Pedrozo Dairy and Cheese Company near Orland makes a Gouda-style farmstead cheese from a small herd of Jersey cows grazed on pasture. The spring milk is used for the production of a seasonally available cheese, aged for 1 year, called Northern Gold-Black Butte Reserve. The Fiscalini Cheese Company in Modesto makes traditional 60-pound wheels of cheddar from their Holstein herd; the cheese is cloth-wrapped and aged between

18 months and 2 years. Redwood Hill Farm in Sebastopol makes several goat cheeses in a French style. One is a California Crottin similar to the French Crottin de Chavignol - a small, cylindrical cheese with a golden-colored edible rind. 
Current U.S. consumption of cheese is estimated at about 30 pounds per person annually, a 20\% increase since 1990. In California, mozzarella - primarily destined for pizza - represented $44 \%$ of all cheese produced in 2001. U.S. consumption still lags behind traditional cheese-loving countries such as France, where the average annual cheese consumption is 54 pounds per person (CMAB 2002).

Our project was conducted under a U.S. Department of Agriculture (USDA) Western Region Sustainable Agriculture Producer/Marketing Grant, to assist small-scale artisan cheese makers. The objective was to gather information about the shopping habits and opinions of specialty cheese consumers that will help cheese makers develop successful strategies to target that market segment. We conducted telephone surveys, focus group interviews and in-store consumer evaluations of point-of-sale materials.

The telephone survey and focus group participants were recruited through sign-up sheets posted at specialty food departments in one gourmet specialty store in Chico and one grocery store each in Sacramento and San Francisco. Forty-seven telephone interviews were conducted in which consumers were asked about the types of cheese they purchased, the country or region of origin, frequency and quantities purchased, and awareness of cheese manufacturing practices related to raw milk. Of those surveyed, 34 also

TABLE 1. Percentage of specialty cheese consumers $(n=47)$ who purchased various cheese, including those made from non-pasteurized (raw) milk

\begin{tabular}{lr} 
Milk class & $\%$ \\
\hline Cow & 100 \\
Goat or sheep & 96
\end{tabular}

Manufacturing method

Aged hard cheeses

(Parmesan, Asiago, Gouda) 98

Veined cheeses

(Roquefort, Stilton, blue)

Soft surface-ripened cheeses

(Brie, Camembert)

Fresh cheeses (chevre, queso blanco)

Pasteurization process

Purchased raw milk cheeses (any type)?

Yes

No

Don't know

38

17

45
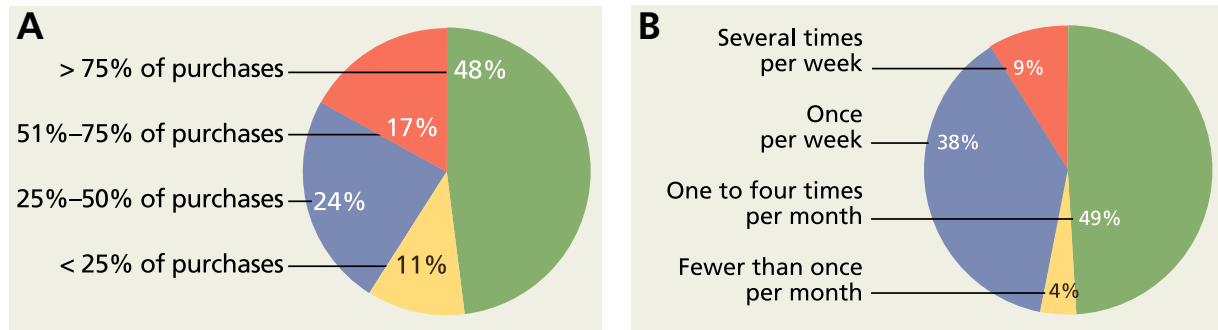

Fig. 1. (A) Specialty cheese purchases as a percentage (by weight) of all cheese purchases made by specialty cheese consumers and (B) frequency of specialty cheese purchases, reported in telephone survey $(n=47)$.

participated in four focus groups. Both the telephone questionnaires and focus group questions were developed with the assistance of dairy farmers who also produce specialty cheese, CMAB marketing personnel and independent food industry consultants.

\section{Not your typical shopper}

Before the telephone interviews began, consumers were read a definition of specialty cheese. It read in part: "An example of specialty cheese is a farmstead cheese made in limited quantities by hand. It can be imported or domestic, is usually sold by the pound and the customer decides how much he or she will buy." The telephone interviews revealed that the self-identified specialty cheese consumers are dedicated to the specialty-cheese market segment, with $48 \%$ purchasing specialty cheeses (rather than commodity cheeses) 75\% of the time (fig. 1A). Nine percent shop for specialty cheeses several times each week, and another 38\% at least once a week (fig. 1B). These buying habits are not typical of today's consumer, who looks for convenience in food purchasing and preparation. Specialty cheese consumers are buying small quantities (75\% usually purchased less than a pound) and are concerned about its freshness and quality. When asked to identify the cheese's country or region of origin, most identified Europe (57\%), followed by California (32\%) and other United States (11\%).

Raw milk cheeses. The USDA has considered changing laws related to the production of raw milk cheeses (those made from unpasteurized milk) because fresh cheeses (those that are not aged) made from raw milk have been associated with outbreaks of foodborne illness, including salmonella and lis-teria.
Currently, cheeses made from raw milk and sold in the United States must be aged for at least 60 days. Many producers of artisan cheeses want to preserve traditional cheese-making methods that include the use of raw milk, although the debate in the United States centers on whether the 60-day aging requirement effectively reduces pathogens. At this time, cheeses made from unpasteurized milk (either U.S. or imported origin) must be aged a minimum of 60 days to be legal. We included a question about raw milk cheeses in the phone survey and a more general question in the focus groups to learn whether specialty cheese consumers perceived them as a health risk.

Consumption of cheeses made from raw milk was not a concern for the majority of people we spoke with. Among those interviewed, $45 \%$ did not know if the cheeses they purchased were made with pasteurized milk and hadn't ever thought about it. Another 38\% knew they purchased raw milk cheeses and did not have health-related concerns (table 1).

Varieties purchased. Most varieties of specialty cheese, as categorized by production method, were consumed by more than $90 \%$ of those interviewed. Examples of cheese production types are veined cheeses (Roquefort), soft surface-ripened cheeses (Brie) or fresh cheeses (chevre). The only category with a consumption rating below $90 \%$ was "fresh cheeses" (68\%). This category may have been underreported, as the majority responded in the affirmative to buying goat and sheep milk cheeses, and the majority of goat milk cheeses on the market are fresh cheeses. Consumers may have been less familiar with the other fresh cheeses, such as the Hispanic-style cheese queso 
fresco, that were also mentioned to describe the category.

\section{Focus groups themes}

Each of the four focus groups consisted of eight or nine people who were paid honoraria and served a selection of specialty cheeses for participating. The meetings were tape-recorded with the participants' permission, and full transcripts were created. We used focus groups to determine how specialty cheese consumers perceive, feel and think about how they make cheese purchasing decisions. Common themes and ideas were extracted from each of the transcripts (Krueger 1994). Consumers were asked open-ended questions about how they use and choose cheeses; the type of information they look for on package labels; their thoughts about the quality, flavor or safety of cheeses made from raw milk versus pasteurized milk; and what kind of information they want from store staff. We also asked if there was anything about dairy products and health that influences purchase decisions.

Participants were asked to describe where their cheese comes from (if they knew) and after some meditation, to share their vision of how and where the cheese is made - even if they had never seen a cheese-making room. They were given a chance to create questions for cheese makers and dairy producers in the format of, "If I could talk to the person who actually made the cheese, I would want to know ..." or "If I could talk to the farmer who owned the cows that provided the milk for my cheese I would want to know ..." Finally, we asked some sociopolitical questions about food production and buying habits. Consumers were asked to rate the importance of buying foods that are organic, locally produced, purchased directly from family-owned farms and produced in a sustainable manner. Once they had rated the importance of each sociopolitical question from "very important" to "don't think about it," we discussed their responses as a group.

\section{"Food experimenters" like samples}

Responses from the focus groups established that consumers do not rely on packaging to make initial purchasing

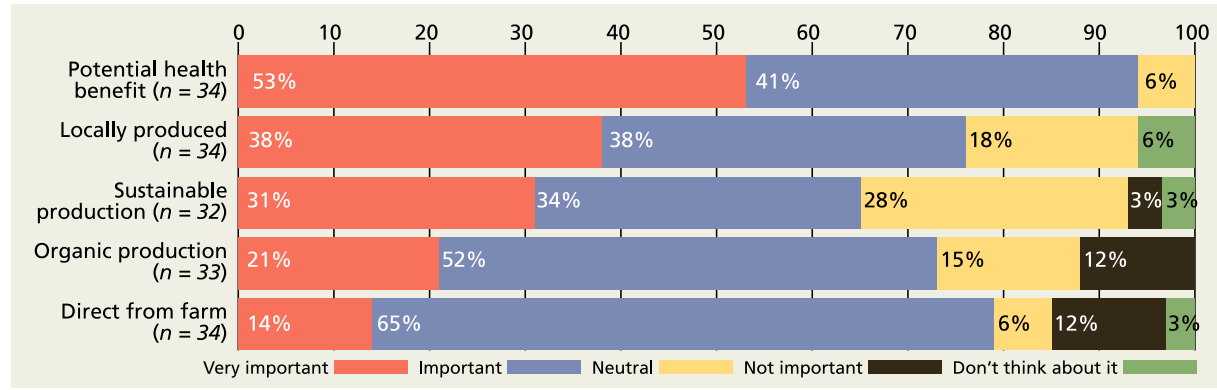

Fig. 2. Importance of sociopolitical factors influencing specialty cheese purchases among focus group participants (in some cases, figure may not add up to $100 \%$ due to rounding error).

decisions. Specialty cheese consumers expressed a strong preference for sampling cheese before they purchase it and said they use tasting and staff recommendations for cheese selection. Consumers indicated that they appreciate unlimited sampling in an unhurried, low-pressure environment and consider themselves "food experimenters." Store staff members can have a significant impact on sales, both through a high level of service and a broad knowledge of their products. If a cheese was highly recommended by the sales staff, and if the staff provided a sample for tasting, consumers we spoke with said they often purchased a type of cheese (blue-veined cheeses, for example) they ordinarily wouldn't buy or had never tried. They often left the store with one or two cheeses not on their shopping list as a result of the staff recommendations or sampling.

Participants consumed cheese as an appetizer, ingredient in salad and cooked dishes, and snack food. They also included cheeses as a dinner course - a practice in European households and restaurants that is just now becoming popular in the United States.

Specialty cheese consumers told us they are not reading labels to find lowfat and low-sodium cheeses. They look for a description of the cheese flavor and characteristics, country of origin, storage, ripening and aging information, food pairings and "sell by" date. Fat content confirms quality and taste attributes, and participants specifically avoid purchasing low-fat cheeses. These consumers are aware of the consequences of excessive consumption of certain foods and believe the quality of a high-fat food must be very high before they will commit an allotment of fat and calories to cheese. Many of the participants mentioned that their focus is on the quality and not the quantity of food they consume.

The focus group responses about food safety were consistent with the telephone surveys. Most specialty cheese consumers are not concerned about the potential health issues related to consuming raw milk cheese. Those who choose to purchase raw milk cheeses often do so for a perceived complexity of flavor not found in pasteurized cheeses, or because they believe the process is more natural or traditional.

\section{Cost not an issue}

Few consumers in any of the groups volunteered information about the pricing or cost of artisan cheeses, except if they were buying for children. These consumers make no effort to economize when they are buying artisan cheeses, although a few of them have experienced sticker shock when they reached the checkout stand. For this market segment, purchasing decisions are driven by the occasion and are guided by flavor and use. In most specialty cheese cases, where the cheese is displayed in whole wheels and cut and wrapped to order, prices are not displayed. The buyer must ask about the price if it concerns them. Retail prices for specialty cheeses range anywhere from $\$ 6$ per pound to more than $\$ 30$ per pound.

\section{Sociopolitical concerns}

Focus group participants were asked to use a printed form to rank the importance of several sociopolitical factors related to food production and purchases, such as potential health benefits, sustainable and organic farming and locally produced food. After they wrote down their responses, we discussed the rankings so people could qualify their choices. Most of the sociopolitical issues 
received a very important or important rating (fig. 2).

In qualifying their statements, specialty cheese consumers brought up two factors that override their philosophy when it comes to their buying habits. First, their purchasing decisions are tempered by time constraints and convenience. For example, $50 \%$ of the San Francisco participants thought buying locally produced foods was important or very important, and 38\% thought that buying direct from family-owned farms was important or very important. While these numbers reflect strong support for locally grown foods, they also indicate that direct access to farms is more of a challenge for residents of San Francisco than of Sacramento or Chico. The average response across all groups for these two questions was higher, at $68 \%$ and $80 \%$, respectively. San Francisco importance ratings for the non-access issues of organic and sustainable food production and health benefits of foods were as high as the other focus groups.

In the list of sociopolitical questions provided to participants, we did not include a question about product quality or freshness. However, all the groups qualified their comments on sociopolitical issues with the statement that the actual and perceived quality and freshness of the product were more important factors than whether it is organic, sustainable or made locally. Specialty cheese consumers may try to support organic or local production, but not at the expense of perceived quality, freshness or flavor. Here, again, their ideals were not always perfectly reflected in their shopping habits. Furthermore, "quality" and "freshness" were self-defined terms that we did not ask participants to explain.

Fifty-three percent of the participants rated "Buying foods that have potential health benefits" as very important, and $41 \%$ said it was important. Related to health concerns, participants brought up questions about the source of the milk used for cheese-making and what was "put into" the cheese besides milk. "Antibiotic-free" and "hormone-free" foods are also important to the specialty cheese consumer. When asked what they would like to discuss if they could talk to the person raising the cows that

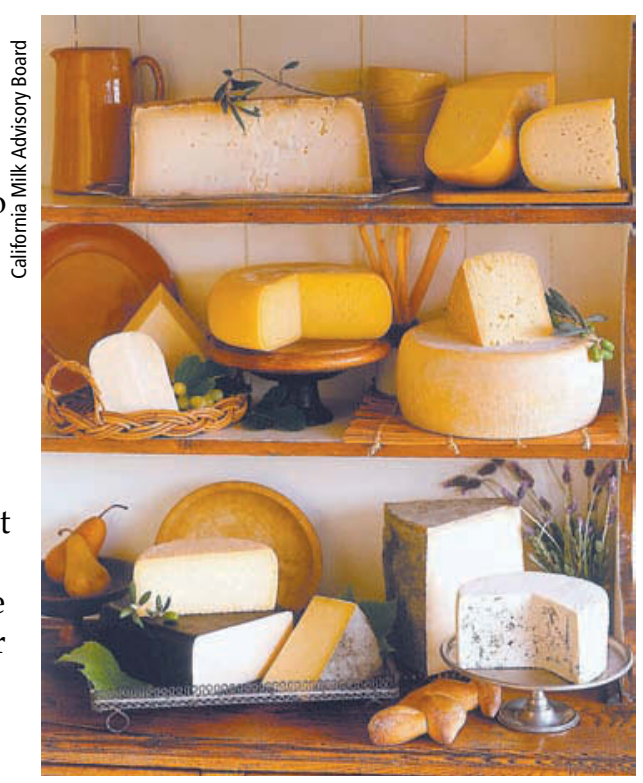

Specialty cheese consumers said they appreciate narratives about how, where and by whom the cheese was made. Makers of farmstead cheeses - made from milk produced on the farm where cheese is made can take advantage of this marketing opportunity.

Some California farmstead cheeses include:

1. Serena, Three Sisters Farmstead Cheese Co. 2. Gouda (medium), Winchester Cheese Co. 3. St. John, Fangundes Old-World Cheese. 4. Northern Gold, Pedrozo Dairy \& Cheese. 5. St. George, Joe Matos Cheese Factory.

6. Giana, Spring Hill Jersey Cheese.

7. Cheddar (sharp), Bravo Farms.

8. Cloth-wrapped Cheddar, Fiscalini Farms. 9. Original Blue, Point Reyes Farmstead Cheese.

provide milk for their cheese, respondents mentioned antibiotics and hormones 12 times and grazing and pasture nine times.

\section{Narrative descriptions sell}

Focus group participants also told us that effective "narratives" about a product would influence their purchase, even if they were not initially inclined to buy the cheese. For example, one said, "I don't think you can underestimate narrative. You hear a story about a 90-year-old cheese maker up in the mountains, and even if it's really strong cheese that I might not normally buy, I might try it. It has everything to do with the person selling me the cheese."

Another noted, "I usually like to know where the cheese comes from, like where the wine comes from. In Europe, certain cheeses have to come from cows that are grazing at a certain altitude or higher. That's where the tradition comes in, which has lasted for several centuries."

"The best cheese I ever had," another participant noted, "was probably while I was driving across the German border to Austria, and I stopped by a little farm that made everything by hand. They had all kinds of cheeses they make themselves. I couldn't resist them."

These consumers have a romantic vision of cheese production and associate specialty cheeses with European cheese-making traditions. Small (family) farms were mentioned often. The participants evoked images of stone cottages and rolling green hills. Traditional European cheese shops such as Neal's Yard Dairy in London were also mentioned.

This love of narrative is a marketing opportunity not to be missed by farmstead cheese makers. Stories about the cheese makers and their farms should be conveyed to the customer. Retail shops can use feature boards or descriptive case cards, or the store staff can relate the narratives directly to customers. A feature board is a chalk or dry-erase board hung behind the counter with weekly specials or featured items written on it. A case card hangs or stands in a refrigerator case (maybe on a peg in the cheese) and is usually large enough to provide a verbal description of the cheese, its origin and some food pairings.

Cheese makers had hoped the focus groups could help guide them in designing effective labels that would highlight dairy practices. We found that labels are not essential to the purchasing decisions of specialty cheese consumers, but they do want accurate and sufficient information (including narratives) to guide cheese selection. This may also be provided by store staff or written on a feature board or

refrigerator case cards.

To follow up on what we learned in the focus groups about narrative descriptions, we developed a series of four case-card statements, each of which described the same cheese in a slightly different manner. We then set up a cheese tasting table in the deli section of two 
TABLE 2. Proposed case-card statements, ranked by specialty cheese shoppers ( $n=36)$ from 1 (most likely to influence purchase) to 4 (least likely)

\begin{tabular}{l|l}
\hline \hline Statement & Mean \\
\hline Pedrozo Peppercorn is a Gouda-style cheese, handmade in limited quantities & $1.83 b^{*}$ \\
by Tim and Jill Pedrozo. The Pedrozo family ages this cheese over 60 days. \\
This cheese is great as an hors d'oeuvre or on top of a salad. \\
\hline $\begin{array}{l}\text { Pedrozo Peppercorn is a smooth, rich Gouda-style cheese made exclusively } \\
\text { from the milk of Jersey cows grazed on organic pastures. This semi-hard cheese }\end{array}$ \\
has a mild flavor accented with pepper. & $2.04 a b$ \\
\hline Pedrozo Peppercorn is a Gouda-style cheese accented with Indonesian & \\
peppercorn. It is made on a small family farm in Northern California. & $2.63 a b$ \\
The milk for this cheese is produced without rBST. & \\
\hline Pedrozo Peppercorn is a semi-hard Gouda-style cheese made exclusively & $2.79 a$ \\
from the milk of Jersey cows. The Pedrozo family ages this raw-milk cheese & \\
\hline over 60 days. &
\end{tabular}

* Means with different letters are significantly different from each other $(P=.0082)$

specialty grocery stores in Sacramento and asked customers to evaluate the marketing effectiveness of the product descriptions on the case cards. Thirtysix people participated in the case-card evaluations.

Consumers were asked to select the case-card statement that would most likely prompt them to purchase a cheese they sampled for our project. The description order was randomized on the survey sheet to avoid skewing the response. The card that described the cheese as "handmade," mentioned the farm family by name and included a serving suggestion received the highest rating and was significantly different from the case card $(P<0.01)$ with the lowest rating (table 2). Only the written descriptions influenced the response. Neither the store location nor the clientele frequenting the store contributed to the statistical variation seen in the response. The data were analyzed by a blocked ANOVA and the means tested by Tukey's Studentized Range.

\section{Marketing strategies}

Who better to tell the story of the product than the maker? Focus group responses showed that cheese makers need to establish a relationship with customers directly or through cheese buyers and distributors. A large part of this strategy can be accomplished through an effective narrative.

Cheese makers should try to have a physical presence at in-store demonstrations so that customers and store employees can get to know them personally. This personal time can be costly, but it is essential to establish the product origin as distinctly different from Kraft Singles. Mass media advertising for Real California Cheese is conducted by the CMAB and paid for through check-off dollars (assessments on each pound of cow's milk produced, as regulated by California's milk marketing order), so in-person promotions by the cheese maker are an important means of differentiating a specialty product. Members of the sales staff need to know as much as possible about the cheese, who the cheese makers are and what the farm is like, including farming practices and animal care and feeding. If cheese makers are selling through a distributor, they should be sure to educate the distributor about their product, provide sales materials for retailers and conduct in-store demonstrations whenever possible.

Increased sales are the incentive for the specialty store staff to set up tasting demonstrations with cheese makers and provide cheese samples for their customers. Such staff often rotates featured cheeses and can use features to derive multiple sales in the same product category. For example, if an aged Italian cheese such as Parmigiano Reggiano is featured, staff members often provide other aged dry cheeses to customers for comparison and purchase.

If cheese is sold in individual packages rather than cut from a wheel, packaging will help the consumer identify a known brand, but they will generally not select a novel cheese based on packaging alone. Other in-store displays such as chalkboards or case cards influence consumer purchases and should contain as much information as possible about the cheese and the cheese makers.

Although we did not survey restaurants, cheese makers told us that they are establishing relationships with chefs in the same ways that they get to know retail customers. Cheese makers usually give their product to restaurants to use as an introduction and work with the chef to develop appropriate recipes or place the cheese as one selection in a cheese course.

It took almost 30 years for California to evolve from the jug wine capital of the United States to a state known for its fine wines (see page 71). The wine industry built its reputation by creating products on a small scale that were equal or superior to European wines in the same price categories. At the 2002 American Cheese Society competition in Washington, D.C., one-quarter of the 100 cheese makers submitting entries were from California. The cheese rated best of show was produced in California, and California cheeses took home prizes in 15 of 22 categories. Although the California artisan cheese industry is still in its infancy, like the wine industry of the 1970s, it has lots of room for growth.

\section{B.A. Reed is County Director and Dairy Farm Advisor, UC Cooperative Extension, Glenn County; and C.M. Bruhn is Director, Center for Consumer Research, UC Davis.}

\section{References}

[CDFA] California Department of Food and Agriculture. 1998. Manufacture of dairy products. California Dairy Statistics Annual 1997. Sacramento, CA. p 25-32. http://134.186.235.120/dairy/pubs/Annual/ $1997 \mathrm{pdfs} /$ manufacture.pdf.

CDFA. 2002. Manufacture of dairy products. California Dairy Statistics Annual 2001. Sacramento, CA. p 25-30. http://134.186.235.120/dairy/pubs/Annual/2001/5.pdf.

[CMAB] California Milk Advisory Board. 2002. The Contemporary American Cheese Course: The New Basics of Eating Well. Workshops for chefs. Las Vegas, Portland, Salt Lake City. CMAB, South San Francisco, CA.

Krueger RA. 1994. Focus Groups: A Practical Guide for Applied Research. 2nd ed. Thousand Oaks, CA: Sage. 255 p. 